\title{
Fatty acids linked with dyes and corrosion inhibitors
}

Oléagineux, Corps Gras, Lipides. Volume 8, Numéro 1, 60-2, Janvier - Février 2001, Dossier : Deutsche Gesellschaft für Fettwissenschaft - Association française pour l'étude des corps gras

\author{
Auteur(s) : Georg FELDMANN, Hans J. SCHAEFER, \\ Westfaelische Wilhelms-Universitaet, Corrensstr. \\ 40, D-48149 Münster, Germany.
}

Summary : 4-Hydroxy- and 4,4'-dihydroxyazobenzene have been linked to methyl oleate by hydroxylation with singulett oxygen and Mitsunobu-reaction. The oleate-dye conjugates exhibit low critical micelle concentrations (10-5 to $10-7 \mathrm{~mol} / \mathrm{l})$, a large reduction of the surface tension (29 to $31 \mathrm{mN} / \mathrm{m}$ at $\mathrm{cmc}$ ) and can dye a nonpolar fiber from aqueous solution. Reaction of methyl epoxystearate and -undecanoate with imidazole, mercaptobenzothiazole and triazole affords fatty acid, corrosion inhibitor conjugates. In an electrochemical test by cyclovoltammetry these conjugates exhibit a better inhibiting efficacy than mixtures of the components.

Keywords : conjugates, surfactants, dyes, corrosion inhibitors.

Résumé : L'action de l'oléate de méthyle avec le 4-hydroxy et le 4,4'-dihydroxyazobenzène lors d'une réaction d'hydroxylation en présence d'oxygène singulet et par la réaction de Mitsunobu permet d'obtenir de nouvelles espèces contenant une partie de type oléate et une autre responsable de la couleur. Les composés présentent des concentrations micellaires critiques faibles (10 - 5 à $10-7$ $\mathrm{mol} / \mathrm{l}$ ), une réduction importante de la tension de surface (de 29 à $31 \mathrm{mN} / \mathrm{m}$ pour un cmc donné) et peuvent teindre une fibre apolaire dans une solution aqueuse. Méthylépoxystéarate et -undecanoate peuvent réagir avec l'imidazole, le mercaptobenzothiazole et le triazole pour donner un composé constitué de deux parties: I'une de type acide gras, l'autre de type inhibiteur de corrosion. Une analyse électrochimique par voltamétrie cyclique a permis de montrer que ces molécules avaient une activité inhibitrice plus grande que les mélanges des réactifs.

Mots-clés : surfactants, agent colorant, inhibiteurs de corrosion.

\section{ARTICLE}

Metal corrosion takes place at the metal/air - and metal/water - interface. This process is affected by corrosion inhibitors that are therefore especially needed at the metal surface. As fatty acids and their derivatives accumulate at interfaces, we concluded that a substance should become surface-active by binding it to a fatty acid as a fatty acid conjugate. This connection should cause these substances to accumulate at interfaces which could intensify their effect there (Figure 1). 


\section{Fatty acids linked with dyes}

Coupling of fatty acids with dyes should lead to coloured surfactants. Surface-active azo and stilbene dyes have been prepared before and their monolayer behaviour has been studied. In these cases the dye has been attached via an ester bond to 12-hydroxystearic acid [1]. In order to establish a more inert link that is resistant against acidic and alkaline hydrolysis we connected an azo dye by way of an ether bond to an octadecenoic acid derived from methyl oleate.

Oleic acid was coupled with phenolic azo dyes by allylic oxidation followed by a Mitsunobu-reaction (Figure 2).

Two fatty acids attached to one azo dye became available by using the same route and choosing 4,4' dihydroxyazobenzene as precursor (Figure 3).

The sodium salts of the fatty acid linked to dyes proved to be surfactants. They are soluble in water yielding yellow solutions that foam upon shaking. These solutions were investigated by tensiometric measurements (Figure 4, Table).

The fatty acid-dye conjugates $1 \mathrm{a}, \mathrm{b}$ and $2 \mathrm{a}, \mathrm{b}, \mathrm{c}$ form micelles at lower concentrations than sodium oleate probably due to the larger hydrophobic portion in the molecule (Table).

Aqueous solutions of these fatty acid conjugates dyed the apolar PAN-fiber (Dolan ) [2]. Part of the dye was released in alkaline solution. However by treatment with an aqueous solution of polydiallyldimethylammonium chloride the dye conjugate remained fixed at the fiber also in alkaline solution.

\section{Fatty acids linked to corrosion inhibitors}

Due to the enormous damages and financial losses caused by corrosion a number of ways for the protection of metal surfaces have been developed. Among other measures corrosion inhibitors are used for temporary protection. They can form a barrier at the surface against the corrosive medium or trap protons or oxygen.

Linking corrosion inhibitors with fatty acids could yield products that combine the water repelling properties of the fatty acid with the protection by the corrosion inhibitor and at the same time could enrich the inhibitor at the metal surface. The corrosion inhibitors were covalently attached to fatty acids by nucleophilic ring opening of the corresponding epoxides (Figures 5 and 6). Saponification of the ester yielded the conjugates. We supposed a poor solubility of carboxylates in tap water due to the precipitation of the corresponding calcium and magnesium salts and prepared additionally the sodium sulfates that are insensible against these cations. For that purpose the secondary hydroxyl group originating from the epoxide was treated with chlorosulfuric acid and the sulfate neutralized with sodium hydroxide.

Copper and its alloys are often protected by mercaptobenzothiazole and triazoles which were coupled with fatty acids using the same route (Figure 7).

The effect of the conjugates with imidazole [3] on iron corrosion was studied using an electrochemical method published by K. Saurbier $[4,5]$. 
In this test the cyclovoltammogram of a steel electrode is recorded that is exposed to standardised tap water $\left(3 \mathrm{mmol} \mathrm{CaCl}, 0.54 \mathrm{mmol} \mathrm{MgSO}_{4}, \mathrm{pH}=9.4\right)$ saturated with air. The features of the cyclovoltammogram can be interpreted as follows (Figure 8). On contact with the alkaline solution an oxide film forms that protects the metal from further corrosion. When the potential rises only low current densities are recorded due to this passivation until the anodic break-through potential is reached, where the oxide film is damaged. Then the unprotected metal areas start corroding and an increase of the current is observed. As a consequence of this continued pitting corrosion the current increases even during the cathodic scan. When the potential is further decreased to a critical value repassivation occurs and the current decreases. In the presence of inhibitors similar cyclovoltammograms are recorded which show a decrease of the maximum current in the cathodic sweep. The efficiency of the inhibitor can approximately deduced from this decline.

We first investigated the conjugates with the sodium salts of the fatty acid in an aqueous $\mathrm{NaCl} / \mathrm{Na}_{2} \mathrm{SO}_{4}$ solution instead of tap water to prevent the precipitation of calcium carboxylate. Thereby the conjugate proved to be a more effective inhibitor than the single components or their mixtures (Figure 9).

Subsequent experiments in standardised tap water $\left(3 \mathrm{mmol} \mathrm{CaCl}, 0.54 \mathrm{mmol}_{2} \mathrm{MgSO}_{4}, \mathrm{pH}=9.4\right)$ proved that the conjugates are also soluble in hard water and inhibit corrosion more efficiently than sodium benzoate (Figure 10).

The position of the inhibitor in the alkyl chain of the fatty acid affects the inhibiting effect of the conjugate. Placing the inhibitor at the end of the alkyl chain increases the efficacy while positioning it close to the polar sulfate group decreases the inhibition.

\section{CONCLUSION}

Dyes attached to a fatty acid combine properties of dyes and surfactants which can be used for dyeing nonpolar fibers from aqueous solution. Fatty acid conjugates with corrosion inhibitors show a higher inhibiting activity than the single components.

\section{Acknowledgements}

Support of the work by the minister of agriculture and forestry of the Federal Republic of Germany (Ref.-Nr. 97NR173-F) is gratefully acknowledged.

\section{REFERENCES}

1. HEESEMANN J (1980). Studies on monolayers: surface tension and absorption spectroscopic measurements of monolayers of surface-active azo and stilbene dyes. J Am Chem Soc, 102: 2167-81.

2. Polyacrylonitrile fiber produced by BASF AG and sold under the trade name Dolan.

3. SRHIRI A, ETMAN M, DABOSI F (1996). Electro- and physiochemical study of corrosion inhibition of carbon steel in $3 \% \mathrm{NaCl}$ by Alkylimidazoles. Electrochim Acta, 41: 429-37.

4. SAURBIER K, SCHULTZE JW, GEKE J (1994). Temporary inhibitors of corrosion in wet atmosphere: electrochemical investigation of the mechanism and efficiency. Electrochim Acta, 39: 1171-8. 
5. SAURBIER K, MENDORF K, SCHULTZE JW, GEKE J (1992). Toluylalanine as an inhibitor of atmospheric corrosion. J Corr Sci, 33: 1351-69.

Illustrations

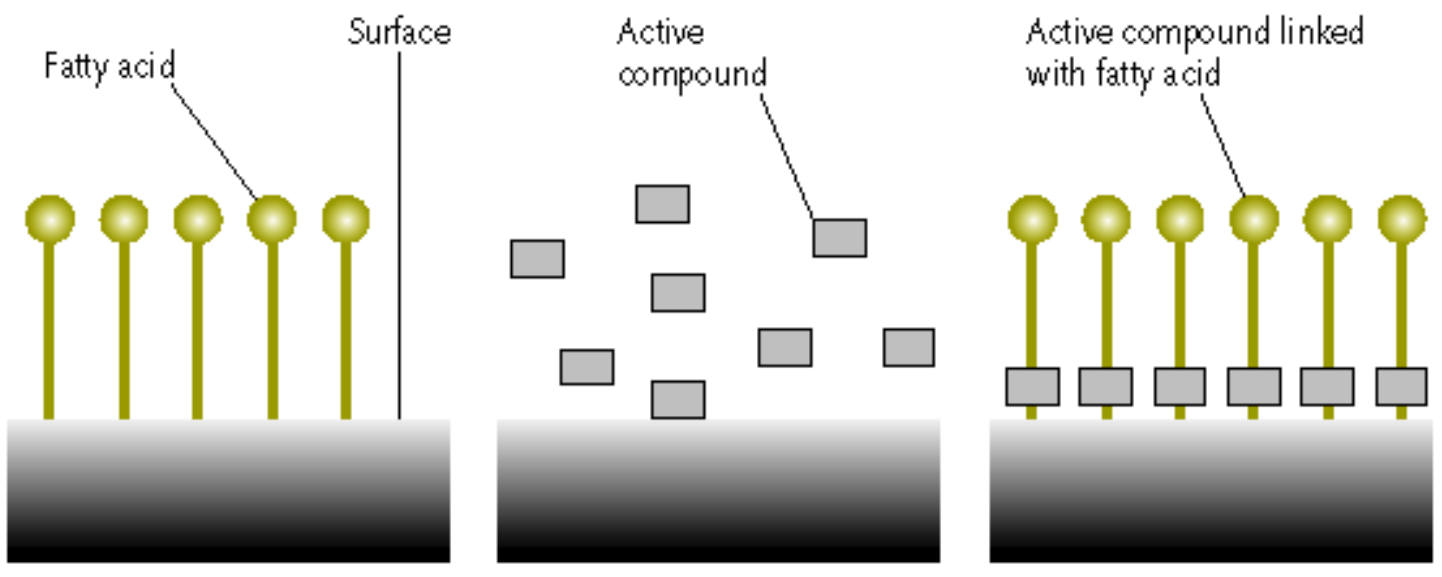

Figure 1. Active substances coupled with fatty acids may accumulate at interfaces.

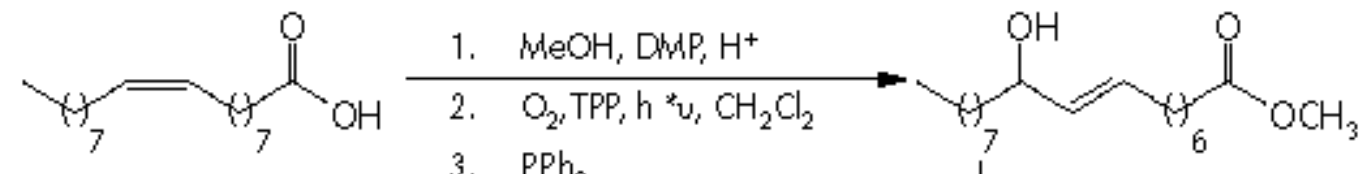

3. $\mathrm{PPh}_{3}$

$86 \%$

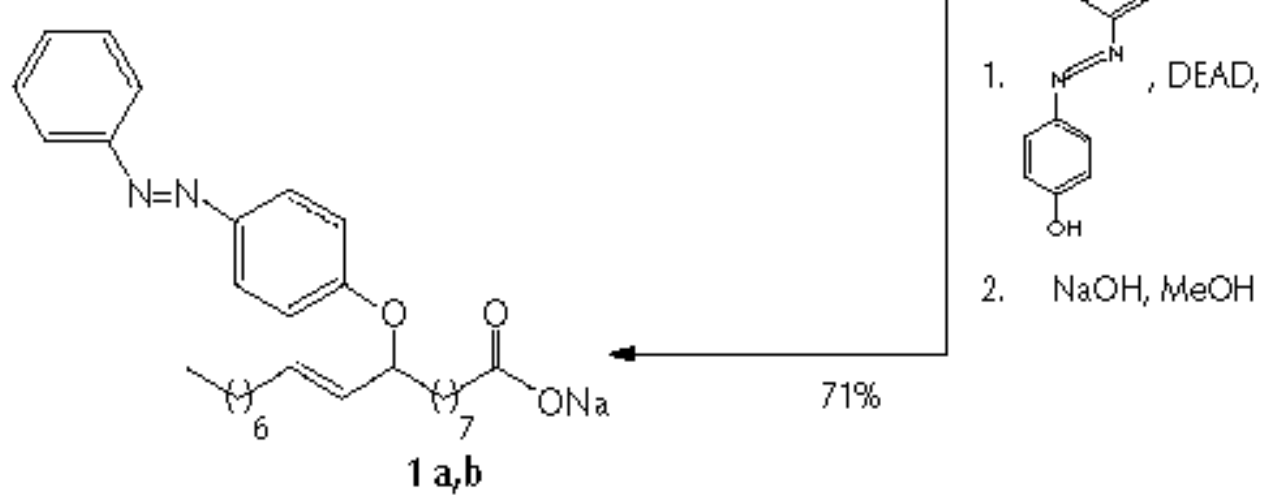

Figure 2. Linking of oleic acid with 4-hydroxy azobenzene via Mitsunobu-reaction. 
<smiles>CCC=CC(O)CC(=O)OC</smiles>

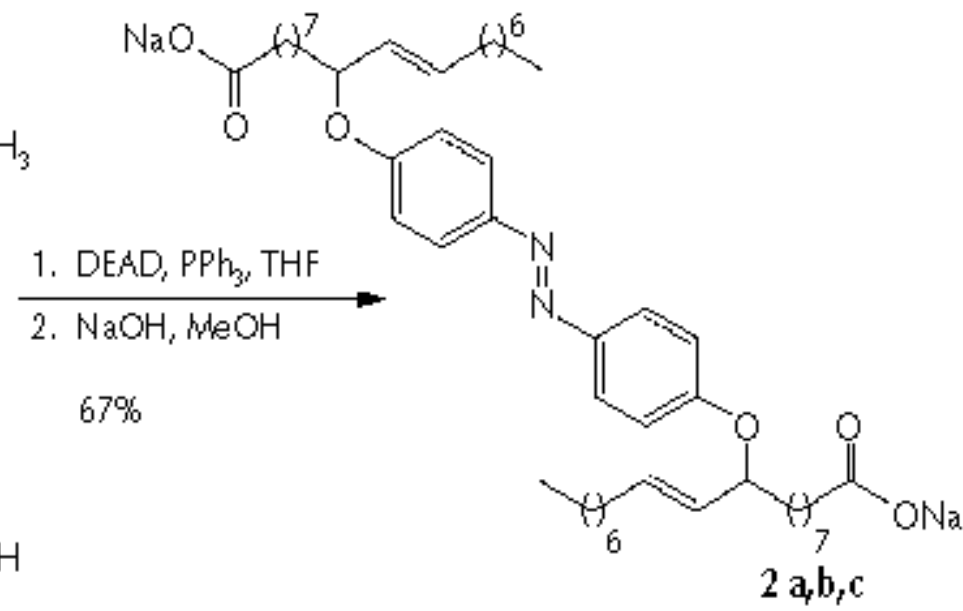

Figure 3. Binding of two oleic acids to 4,4'-dihydroxyazobenzene via Mitsunobureaction.

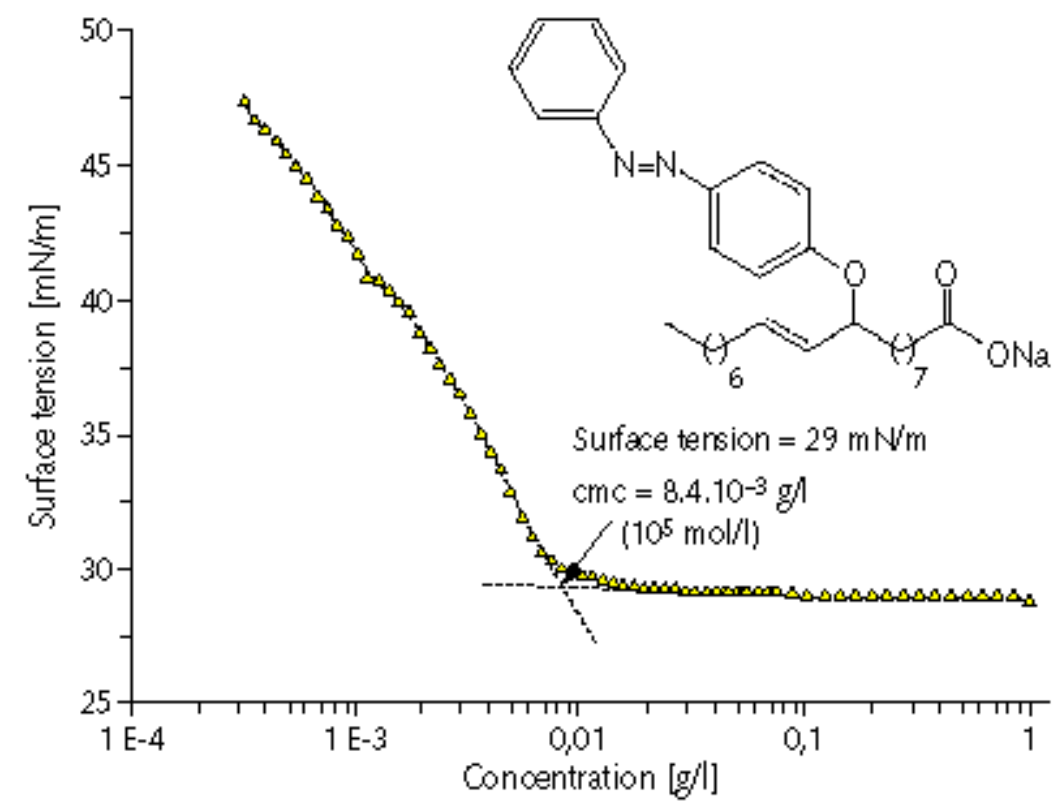

Figure 4. Tensiometry of fatty acid linked with a dye. 

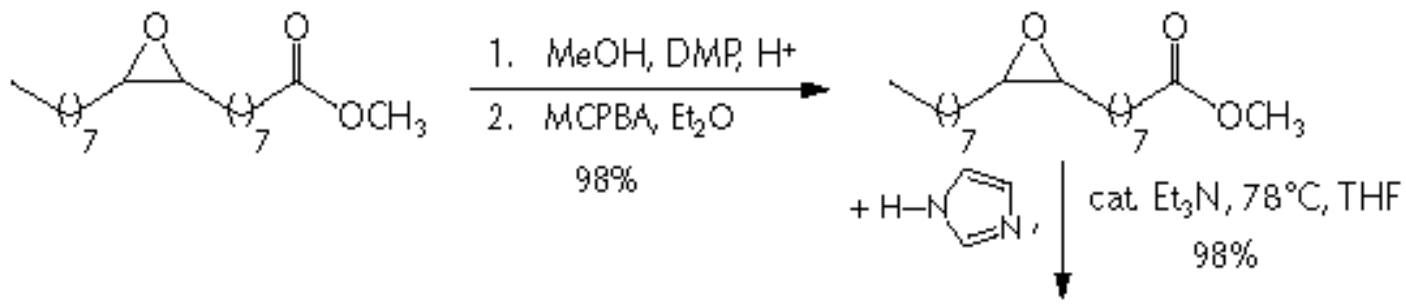<smiles>[Y]C(O)C([Y]C(=O)O[Na])n1ccnc1</smiles>

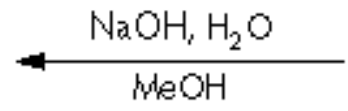<smiles>C=CC(O)C([Te]C(=O)OC)n1ccnc1</smiles>

$87 \% \begin{aligned} & \text { 1. } \mathrm{HClSO}_{3}, \mathrm{Et}_{2} \mathrm{O}, 0^{\circ} \mathrm{C} \\ & \text { 2. } \mathrm{NaOH}_{2} \mathrm{H}_{2} \mathrm{O}\end{aligned}$

$85 \%$

$$
95 \% \mid \begin{aligned}
& \text { 1. } \mathrm{HClSO}_{3}, \mathrm{Et}_{2} \mathrm{O}, 0^{\circ} \mathrm{C} \\
& 2 . \mathrm{NaOH}_{2} \mathrm{H}_{2} \mathrm{O}
\end{aligned}
$$<smiles>[H][Z1]([H])C([Y2](=O)O[Na])n1ccnc1</smiles><smiles>COC(=O)CC(C([Te])O[Na])n1ccnc1</smiles>

DWP: Dimethoxypropane WCPBA: m-Chloroperbenzoic acid 

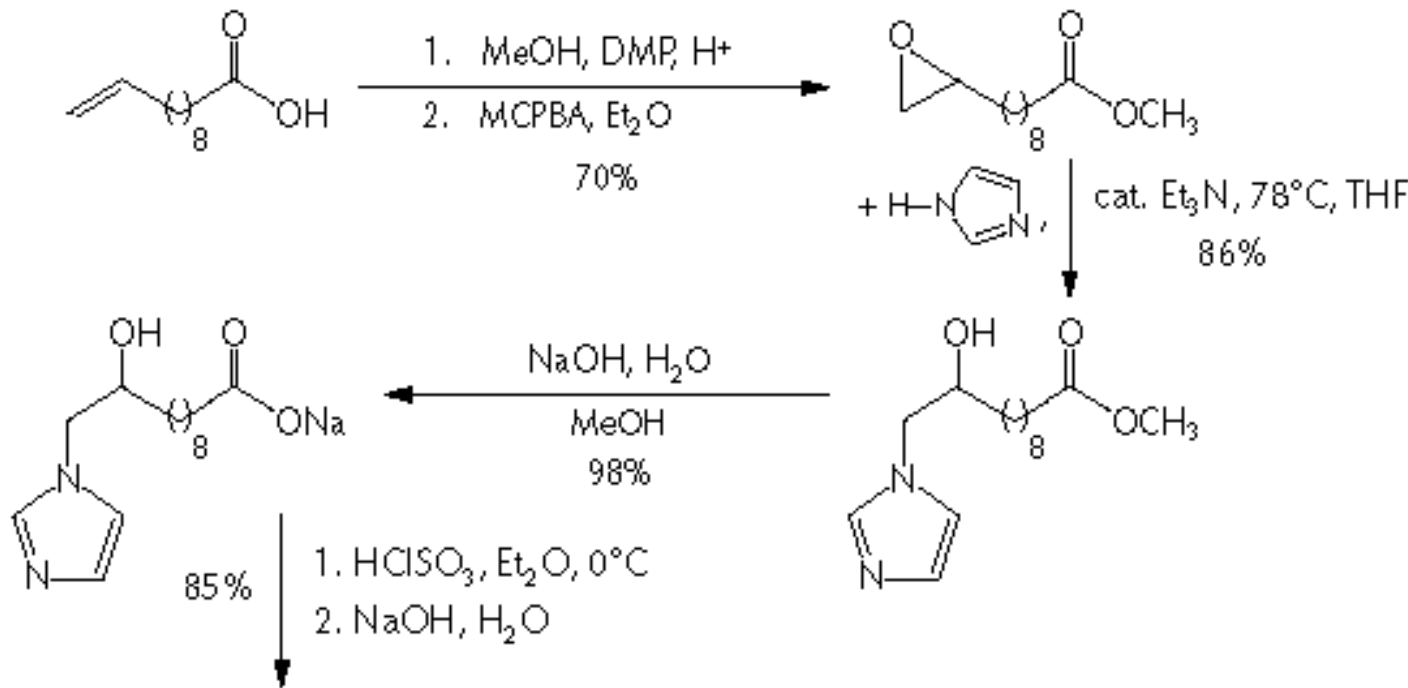<smiles>COC(=O)[18O]C(O)Cn1ccnc1</smiles><smiles>[Y]OC(=O)[Y10]([H])C(Cn1ccnc1)O[N+]([O-])([O-])O[Na]</smiles>

Figure 6. Coupling of the corrosion inhibitor imidazole with methyl epoxyundecanoate. 

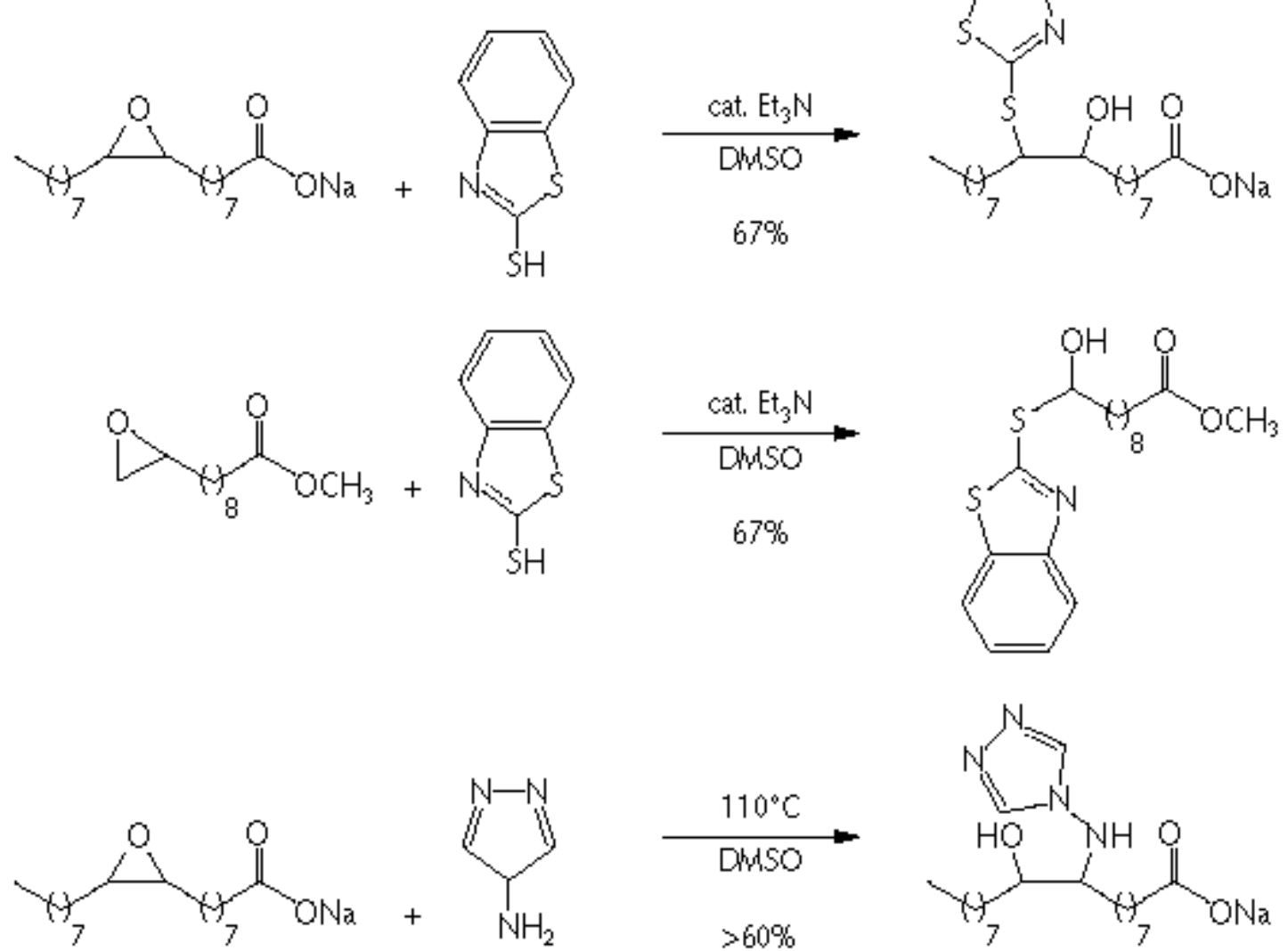

Figure 7. Coupling of epoxy fatty acids with mercaptobenzothiazole and aminotriazole. 


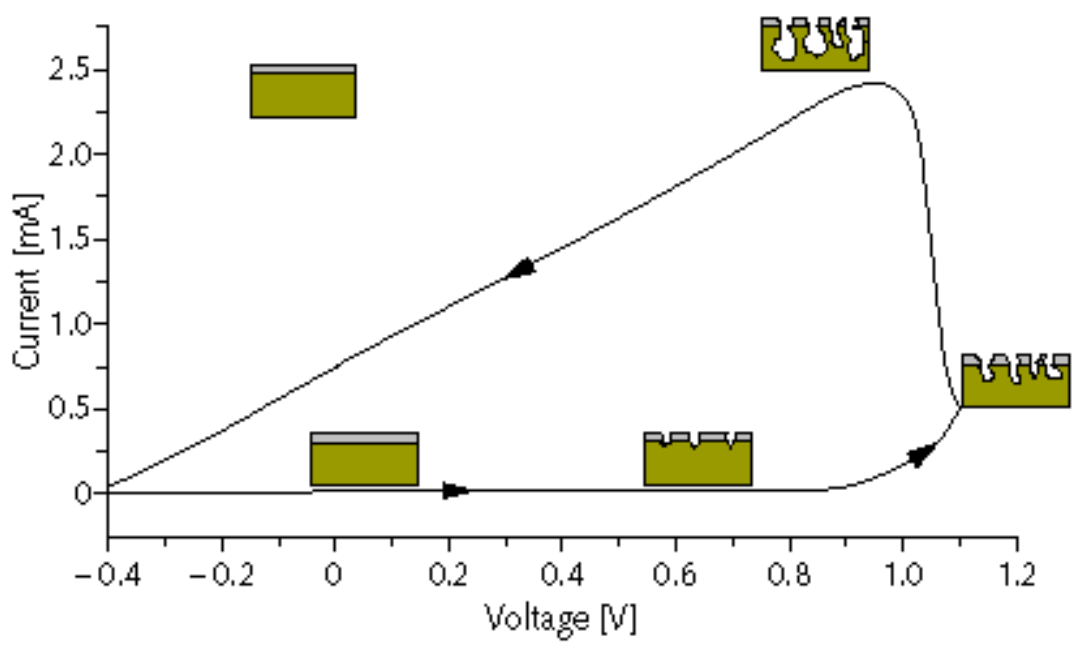

Figure 8. Cyclic voltammetry: corrosion of a steel (ST 37) surface in tap water.

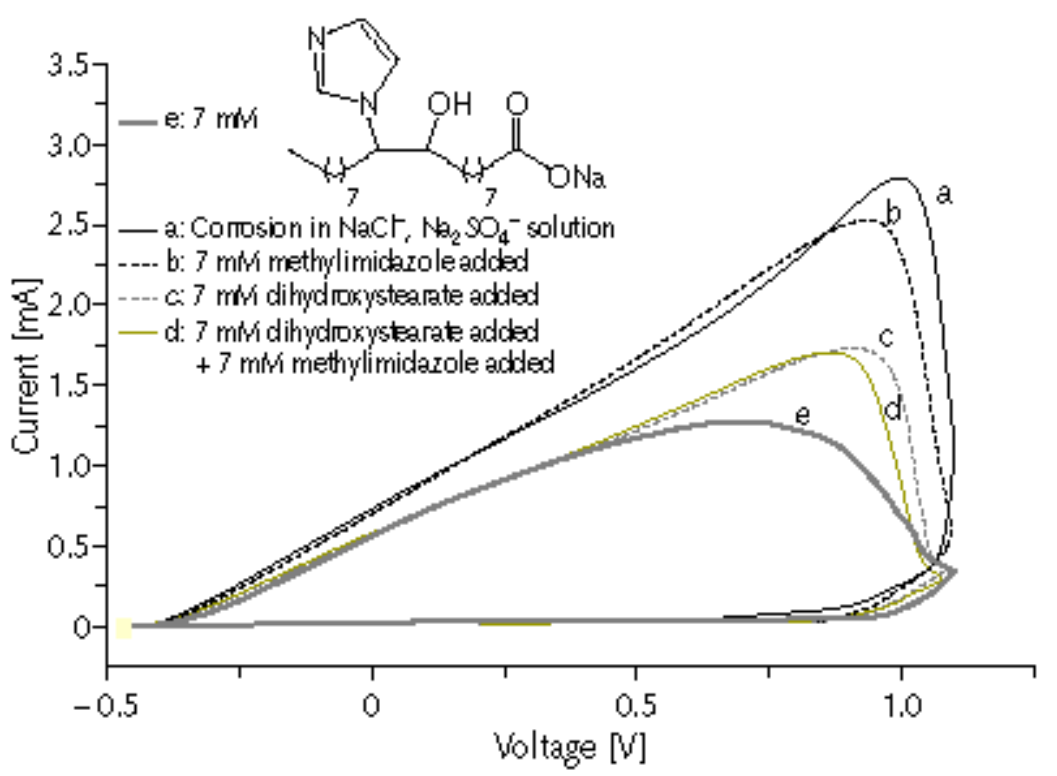

Figure 9. Cyclic voltammetry: corrosion of a steel (ST 37) surface in the presence of different inhibitors in $\mathrm{NaCl} / \mathrm{Na}_{2} \mathrm{SO}_{4}$ solution. 


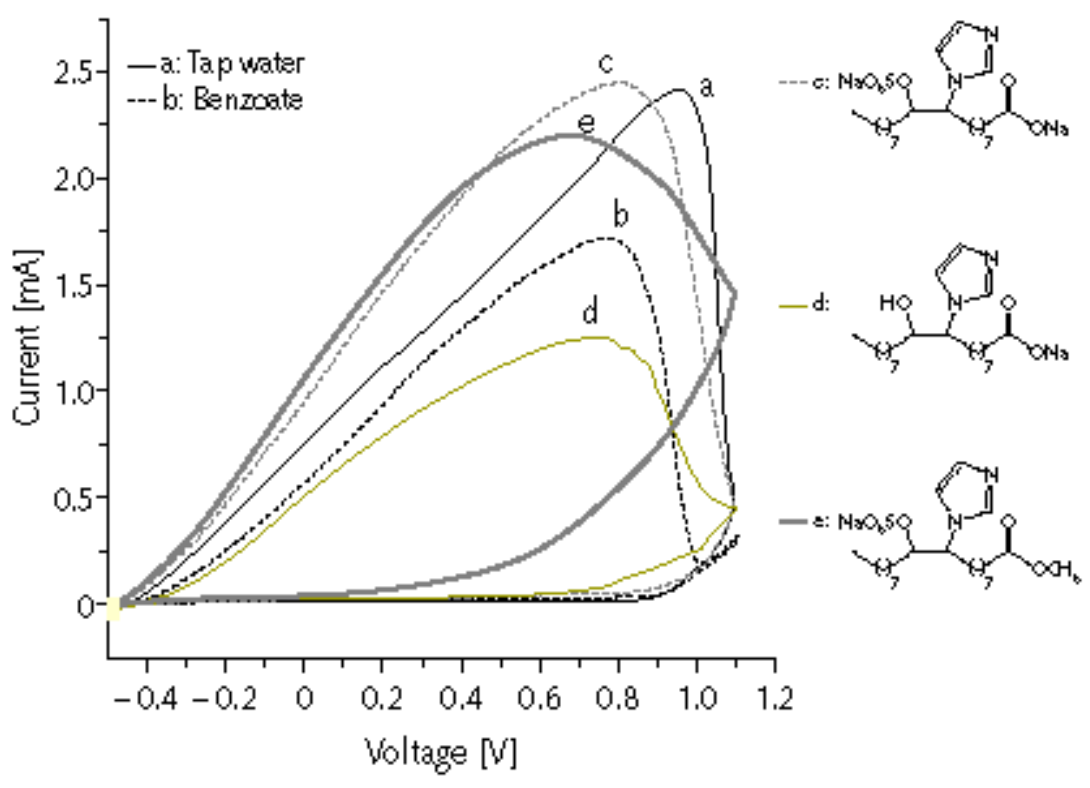

Figure 10. Cyclic voltammetry: corrosion of a steel (ST 37) surface in the presence of different inhibitors ( $7 \mathrm{mM}$ ) in tap water.

Table. Critical micelle concentration and surface tension at the critical micelle concentration of $1 a, b$ and $2 a, b, c$ and sodium oleate.

\begin{tabular}{l|c|c} 
Surfactant & $\mathbf{c m c}(\mathbf{m o l} / \mathbf{l})$ & $\mathbf{\sigma}(\mathbf{m N} / \mathbf{m})$ at $\mathbf{c m c}$ \\
\hline Sodium oleate & $10^{-4}$ & 28 \\
$1 \mathrm{a}, \mathrm{b}$ & $10^{-5}$ & 29 \\
$2 \mathrm{a}, \mathrm{b}, \mathrm{c}$ & $10^{-7}$ & 31
\end{tabular}

